Slavica

bruxellensia

\section{Slavica bruxellensia}

Revue polyphonique de littérature, culture et histoire

slaves

$8 \mid 2012$

Migration(s) et Exil(s)

\title{
Jaroslav Rudišs, La Fin des punks à Helsinki
}

Morgan Corven et Caroline Vigent

\section{OpenEdition \\ Journals}

Édition électronique

URL : http://journals.openedition.org/slavica/1159

DOI : 10.4000/slavica. 1159

ISSN : 2034-6395

Éditeur

Université libre de Bruxelles - ULB

\section{Référence électronique}

Morgan Corven et Caroline Vigent, « Jaroslav Rudiš, La Fin des punks à Helsinki », Slavica bruxellensia

[En ligne], 8| 2012, mis en ligne le 15 juin 2012, consulté le 22 septembre 2020. URL : http:// journals.openedition.org/slavica/1159; DOI : https://doi.org/10.4000/slavica.1159

Ce document a été généré automatiquement le 22 septembre 2020.

\section{(c) (i) () $\Theta$}

Les contenus de Slavica bruxellensia sont mis à disposition selon les termes de la Licence Creative Commons Attribution - Pas d'Utilisation Commerciale - Pas de Modification 3.0 France. 


\section{Jaroslav Rudiš, La Fin des punks à Helsinki}

Morgan Corven et Caroline Vigent

\section{RÉFÉRENCE}

Rudiš J., La Fin des punks à Helsinki, Books Edition, Paris, 2012, 352 p. Traduit du tchèque par Morgan Corven et Caroline Vigent.

« Ici c'est no future, Tchernobyl, les Sudètes et le terminus de toutes les lignes de bus. » (pp. 203-204) 
1 En 1987, aux confins de la Tchécoslovaquie communiste, Nancy, sa crête et son blouson à clous, n'a rien pour plaire au régime. Brimée, persécutée, elle finit même par se faire exclure de l'école. Mais voilà bien le cadet de ses soucis : le pire serait de tomber enceinte à cause de cet idiot d'Helmut. Ou que le mal qui enfle dans sa gorge depuis l'explosion de la centrale Lénine ne s'avère fatale. Car contre toute apparence, et malgré ses difficultés à gérer son identité d'adolescente mi-tchécoslovaque miallemande, mi-trash mi-fleur bleue, l'adolescente de 17 ans espère bien que l'avenir finira par lui sourire.

2 «Le bonheur n'existe pas, ce n'est rien de plus que l'une de nos stupides illusions » (p. 247): avec vingt ans de recul, Ole, lui, a

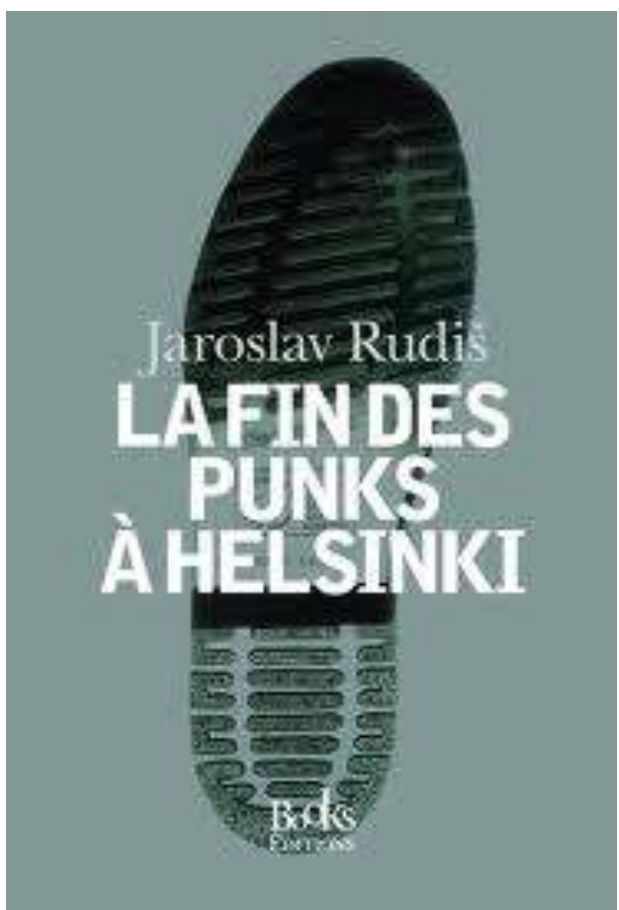
baissé les bras. Cet ancien punk de RDA survit dans l'Allemagne réunifiée de ce nouveau millénaire avec un seul objectif, celui de sauver son bar, le Helsinki, dernier bouge cradingue d'une ville passée aux mains des promoteurs et des non-fumeurs. Une apathie qui ne manque par de hérisser Eva, son activiste de fille :

Ils sont beaux et bio, ils te donnent envie de vomir et jamais tu n'échangerais ta vie contre la leur et tu jures que tu ne leur ressembleras jamais à ces idiots (...), persuadés d'avoir été la dernière génération punk. » (pp. 270-271)

Là où les bourgeois se barricadent derrière leur bien-pensance, et où tout ce qui n'est pas labellisé sans risque doit être éradiqué, la jeune fille a choisi de faire exploser des bombes. Le renouveau du mouvement punk, après la génération des guitares électriques et des crachats?

Ce sont donc trois voix distinctes qui alternent au fil des chapitres dans La Fin des punks à Helsinki, dernier roman du jeune écrivain Tchèque installé à Berlin, Jaroslav Rudiš. Mais inutile de redouter l'apparente anarchie formelle de l'histoire, l'auteur respecte parfaitement la mécanique romanesque: son histoire est jalonnée de leitmotives progressifs, et chaque partie tend à se rejoindre vers un même dénouement. Qu'il s'agisse du récit de ce narrateur mélancolique qui raconte les errances d'Ole, du journal intime et plutôt cru signé Nancy ou du "Manifeste des gens beaux » d'Eva, une longue phrase de vingt pages, telle un seul souffle plein de rage. L'une des plus grandes difficultés de traduction! De même, il aura fallu se familiariser avec le langage parlé des années 1980 de Nancy, et trouver un fonctionnement en français pour les nombreux germanismes dont se sert la jeune bilingue.

4 Ainsi, comme leur langage plus brutal le révèle, l'esprit de rébellion l'emporte chez les filles, en pleine lutte existentielle dans des mondes normalisateurs, qu'ils soient communiste ou capitaliste. En revanche, l'âge et les désillusions ont eu raison de la colère d'Ole, d'où une narration plus sobre, abandonnée à l'ironie, mais aussi souvent plus poétique. Lui qui a passé sa jeunesse à hurler des textes aux accents nietzschéens 
en s'attaquant à toutes les frontières possibles est devenu, campé derrière son bar, le spectateur solitaire de sa ville qui se transforme et de la vie - non-vie ? - des punks de sa génération, une bande de marginaux que la ville moderne a repoussés là : Frank, sans cesse sur le point de terminer son Histoire du monde, Tom, DJ incompris et champion du monde de téléchargement, Le Noyé, Débrouille-toi-tout-seul et Lena, l'éternelle étudiante aux yeux baltes avec qui Ole a peut-être couché, ou peut-être pas.

Comme les hurluberlus qu'il côtoie, Ole est donc prisonnier de ses obsessions et, traqué par son passé et son histoire avec Nancy, rencontrée lors du concert mythique de Die Toten Hosen à Plzen en 1987, il ne compte plus que sur ses "pilules contre la mort " pour apaiser son angoisse. Jusqu'au jour où, n'y tenant plus, il décide de prendre la route - tel l'un des nombreux pèlerins que comporte la littérature tchèque, que l'on pense à Mai de Kárel Hynek Mácha ou à l'Arc de Dieu de Jaroslav Durych - pour retourner sur les traces d'une jeunesse, la sienne et celle de Nancy, envolée avant même d'avoir été pleinement vécue. Car c'est bien là que se trouve la violence romantique du roman, parfaitement exprimée par la jeune fille à crête et son majeur volontiers levé bien haut vers le ciel.

INDEX

Mots-clés : littérature tchèque, punks

Index chronologique : époque contemporaine, XXIe siècle

Index géographique : Allemagne de l'Est, République tchèque, Tchécoslovaquie 